\title{
A DINÂMICA DAS FRONTEIRAS: DESLOCAMENTO E CIRCULACÃO DOS "BRASIGUAIOS" ENTRE OS LIMITES NACIONAIS
}

\author{
José Lindomar C. Albuquerque \\ Universidade Federal de São Paulo - Brasil
}

Resumo: $O$ artigo aborda a dinâmica das fronteiras políticas e sociais a partir das experiências dos "brasiguaios" que vivem em alguns municípios do departamento de Alto Paraná, no Paraguai. Esses moradores fronteiriços se deslocam para o outro lado do limite político brasileiro principalmente a partir da década de 1970 e criam variadas formas de circulação e fluxos transfronteiriços na região da Tríplice Fronteira entre o Paraguai, o Brasil e a Argentina. As relações entre os "brasiguaios" e a população paraguaia têm produzido novas formas de identificações étnico-nacionais e produções de diferenças sociais e de hibridismos culturais nessa complexa configuração fronteiriça.

Palavras-chave: circulação, fronteira, identificação, nação.

Abstract: This article examines the dynamic of political and social frontiers as it pertains the experiences of "brasiguaios" who live in some towns of the Alto Paraná, a province of Paraguay, These frontier villagers have been crossing the Brazilian political borders since the 1970's. They are creating various ways of circulation and border crossing flows in the "Triple Frontier" region between Paraguay, Brazil and Argentina. Relations between the "brasiguaios" and the Paraguayan population have produced new modes of ethnic and national identifications, social differences and cultural hibridities in the context of that complex frontier.

Keywords: circulation, frontier, identification, nation.

A reflexão sobre as fronteiras nacionais durante o século XIX e primeira metade do século XX foi feita principalmente por diplomatas, juristas, geógrafos, historiadores e militares. Os trabalhos estavam centrados em discussões de conflitos de limites, tratados de fronteiras, movimentos expansionistas dos Estados nacionais e redefinições das fronteiras. A referência principal eram os 
agentes dos Estados e seus movimentos de conquista, expansão, demarcação e garantia do território nacional. A palavra "fronteira" estava associada à dimensão militar, territorial e estatal (Mattos, 1990; Soares, 1972).

Nas últimas décadas do século XX e início do século XXI tem havido uma preocupação crescente de antropólogos e sociólogos em olhar as microrrelações das populações locais nas regiões de confluência entre duas ou mais nações. A possibilidade de pensar as nações em seus limites tem contribuído para analisar a articulação entre a esfera local, regional, nacional e transnacional nos espaços fronteiriços e perceber a dinâmica das identificações e das representações sobre o "outro". Esses estudos também têm permitido compreender a instrumentalização da fronteira política pela população fronteiriça - o pêndulo do mercado fronteiriço conforme a cotação das moedas nacionais, as formas de exercício de direitos civis, políticos e sociais nos limites dos Estados nacionais, etc. -, bem como refletir sobre tantas outras fronteiras (sociais, culturais, simbólicas) que se formam, se sobrepõem, se complementam e entram em conflito em relação à noção de fronteira política ou estatal (Abínzano, 2004; García, 2003; Grimson, 2000, 2003).

Os amplos deslocamentos e circulação de pessoas nos territórios fronteiriços possibilitam novas reflexões sobre a polissemia de sentido do termo "fronteira”. Investigo a especificidade dos brasileiros que migraram e migram para os territórios fronteiriços do Paraguai próximos ao limite internacional com o Brasil. Meu intuito é pensar na dinâmica das fronteiras ou fronteiras em movimento em um espaço fronteiriço de forte presença de brasileiros e seus descendentes. A proximidade entre os dois países gera intensos fluxos e produz diversas barreiras e travessias que se cruzam e redefinem a compreensão dos limites nacionais.

\section{0 deslocamento de brasileiros para a fronteira leste do Paraguai}

A presença de brasileiros no Paraguai principia no final dos anos 1950, intensifica-se nas décadas de 1960 e 1970 no contexto de construção da hidrelétrica de Itaipu e continua em novos fluxos nos últimos anos. ${ }^{1} \mathrm{O}$ número de

\footnotetext{
1 Este artigo foi construído a partir de minha tese de doutorado (Albuquerque, 2005). Realizei trabalho de campo em outubro de 2002, janeiro e fevereiro de 2003, outubro de 2004 a março de 2005 nas cidades de Santa Rita, Santa Rosa, Naranjal, San Alberto e Mbaracayú no departamento de Alto Paraná, Paraguai.
} 
brasileiros no país vizinho é impreciso. As estimativas indicam que se trata da maior migração de brasileiros para uma nação fronteiriça e a segunda maior “comunidade de brasileiros” no exterior. Segundo os dados do Ministério das Relações Exteriores, em 2002, dos 545.886 brasileiros que se encontravam nos países da América do Sul, 459.147 estavam no Paraguai. Esse país concentra de longe a maior quantidade, ou seja, mais de 4/5 de todos os imigrantes brasileiros que vivem nos países vizinhos (Diretoria Geral de Assuntos Consulares, Jurídicos e de Assistência a Brasileiros no Exterior, do Ministério das Relações Exteriores apud Sprandel, 2002).

Os imigrantes brasileiros no Paraguai fazem parte de dois amplos processos migratórios no interior do Brasil: um movimento vindo do Rio Grande Sul em direção a Santa Catarina, Oeste do Paraná e Mato Grosso do Sul; um outro fluxo vindo do Nordeste e Minas Gerais em direção ao Estado de São Paulo, Norte e Oeste do Paraná. Essas migrações eram fundamentalmente compostas por famílias de camponeses. As famílias dos dois fluxos migratórios ocuparam geralmente posições sociais diferentes tanto no Oeste do Paraná, Mato Grosso do Sul como no Leste do Paraguai nos ciclos do café, da menta e da soja. Os nordestinos e mineiros se tornaram principalmente peões, arrendatários e posseiros nessas frentes de expansão nacionais, enquanto que os sulistas se constituíram majoritariamente como colonos, pequenos e médios proprietários, especialmente em território paraguaio.

Os imigrantes "pioneiros" comumente migram mais de uma vez em cada geração. As gerações estão em constante movimento. Os pontos intermediários da corrente migratória dos gaúchos são os estados de Santa Catarina e Paraná, ou seja, muitos vivem durante alguns anos naqueles estados antes de irem para o Mato Grosso do Sul e para o Paraguai. Os imigrantes gaúchos e catarinenses são predominantemente descendentes de europeus, principalmente italianos e alemães:

Meu pai vem do Rio Grande do Sul e minha mãe de Santa Catarina, eles se conheceram e se casaram no Paraná. Meu pai veio com nove anos para o Paraná e não sabia uma palavra em português. Ele entrou na escola com nove anos, descendente de italiano e só falava em italiano. Ele aprendeu a falar o português na escola. Ele se criou bem no Sul do Paraná, perto de Santa Catarina. Nasceram quatro filhos lá, inclusive eu, daí a última já é paraguaia, nasceu aqui. (Empresário agrícola, Santa Rita, Paraguai, entrevistado em 17 de novembro de 2004). 
O outro fluxo migratório tem como pontos intermediários São Paulo e o Norte do Paraná, isto é, quase todos os nordestinos e mineiros que vivem atualmente no Paraguai moraram alguns anos em São Paulo e em mais de uma região do estado do Paraná. Muitos dos nordestinos ou "nortistas” vieram no período inicial dessa imigração - décadas de 1950, 1960 e 1970 - para trabalhar no desmatamento das fazendas e no plantio e colheita de menta e café. Muitos deles já voltaram para o Brasil, pois não conseguiram comprar ou ampliar a propriedade rural. Contudo, alguns prosperaram economicamente, como este nordestino que hoje tem uma grande fazenda e é exportador de soja no departamento de Alto Paraná:

No ano de 1960 nós saímos do Nordeste, chegamos no Estado de São Paulo. Era na época das colheitas de amendoim e algodão. Viemos de caminhão pau-dearara. Até São Paulo viemos com nossos recursos. De São Paulo até Presidente Prudente. Trabalhamos 90 dias em Presidente Prudente. Ganhemos um pouquinho de dinheiro, fretemos de novo um outro caminhão. Eram três famílias que estavam juntas. Nós chegamos até Ivailanda, que é uma cidadezinha pequena perto de Maringá [Norte do Paraná]. Em Ivailanda chegamos a trabalhar mais 60 dias, meu pai e meus irmãos. Ganhamos outro pouquinho de dinheiro, fretamos outro caminhão até Goioerê, seria o nosso destino. Viemos e trabalhamos anos e anos em fazendas, daí compramos um pequeno pedacinho de terra em Goioerê, cinco alqueires de terra. A família muito grande, era 11 homens e duas mulheres e meu pai e minha mãe. Com todas as dificuldades que os nordestinos encontram no Sul, encontram dificuldades terríveis, com esse pedacinho de terra que compramos, a família começou a crescer, casar, os filhos começaram a casar. Daí nós viemos para uma cidade quase já nas fronteiras, Assis Chateaubriand. Ali nós moramos dez anos, depois chegamos a Foz do Iguaçu. Em Foz do Iguaçu foi onde eu primeiramente tive esta ideia de passar a ponte na época do militar no Brasil. Antes da construção de Itaipu nós já estávamos entrando no Paraguai e também fomos infelizes, nós tínhamos uma propriedade e fomos desapropriados por Itaipu na chamada Alvorada do Iguaçu e dali nós viemos para Foz do Iguaçu, passamos a ponte para o lado de cá. Hoje está com 27 anos que estamos no Paraguai. (Empresário agrícola, Naranjal, Paraguai, entrevistado em 17 de novembro de 2004).

As estratégias geopolíticas de aproximação entre o Brasil e o Paraguai (construção da ponte da Amizade, hidrelétrica de Itaipu) favoreceram a entrada de muitos brasileiros no território paraguaio. Não podemos concluir 
categoricamente que a presença de milhares de brasileiros na fronteira do Paraguai tenha sido somente obra das políticas governamentais do Brasil e do Paraguai. O que existiu foi uma junção de um processo espontâneo de deslocamento populacional, devido à concentração da propriedade nos estados do Sul do Brasil, com os interesses geopolíticos dos governos brasileiro e paraguaio em controlar e desenvolver a região leste daquele país.

No início desse processo, setores mais marginalizados da frente de expansão interna, bem como alguns grandes produtores agrícolas do Sul do Brasil "saltam o rio Paraná" e começam a colonizar as terras paraguaias. As denominadas modernização e mecanização da agricultura, com a expansão dos plantios de soja na década de 1970, favoreceram o deslocamento de muitos agricultores, posseiros e arrendatários das terras brasileiras próximas à fronteira para o Leste do Paraguai. Nesse contexto, o governo ditatorial do Paraguai efetiva um grande plano de colonização agrícola na região fronteiriça com o Brasil, facilitando a entrada de empresas e colonos estrangeiros nos departamentos fronteiriços. Os desdobramentos da Marcha para o Oeste no Brasil se encontraram com a Marcha al Este no Paraguai a partir da década de 1960.

A Marcha al Este visava reassentar os camponeses que viviam na área central e mais populosa do Paraguai. Para isso foi criado o Instituto de Bienestar Rural (IBR) - atualmente Instituto Nacional de Desarrollo Rural y de la Tierra (Indert) -, responsável pela reforma agrária naquele país, e várias colônias oficiais. O governo paraguaio reformulou o estatuto agrário em 1963 e permitiu a venda de terras aos estrangeiros nas zonas de fronteira. Até o período, essa região tinha uma floresta tropical e era ocupada por grupos indígenas, traficantes de madeira e por empresas de extração da erva-mate, como a Mate Laranjeira. Com a mesma intenção de ocupar os "espaços vazios" e diminuir as tensões sociais da região central, o governo implementou o plano de colonização e facilitou a entrada de brasileiros tanto na derrubada da mata como no plantio agrícola. Dessa forma, os departamentos fronteiriços de Alto Paraná, Canindeyú, Amambay foram ocupados principalmente por colonos brasileiros, enquanto que os departamentos vizinhos de Caaguazu e Caazapá foram colonizados por campesinos paraguaios, que se deslocaram dos departamentos centrais. A expansão dos plantios de soja na atualidade nesses departamentos de muitas colônias campesinas tem ampliado as áreas de contato e atrito entre brasileiros e paraguaios. 
O deslocamento de milhares de trabalhadores para a construção da hidrelétrica de Itaipu e a indenização de vários camponeses que viviam no lugar do futuro lago de Itaipu também contribuíram para aumentar o fluxo migratório para o Paraguai na década de 1970 e 1980 . Calcula-se que só para a construção da usina foram necessários cerca de 40 mil trabalhadores. Para a formação do lago de Itaipu, 42 mil pessoas tiveram de se transferir, sendo 38 mil dentre elas pequenos produtores rurais. Durante esse processo de desapropriação de terras e construção da usina, muitas famílias dos trabalhadores da Itaipu e dos proprietários indenizados se dirigiram para as terras férteis do Paraguai.

Os brasileiros, vindos de diferentes unidades da federação, entraram no Paraguai principalmente através do limite internacional entre o Estado do Paraná e o departamento de Alto Paraná e entre o Estado do Mato Grosso do Sul e os departamentos de Canindeyú e Amambay. Muitos entraram sem nenhum visto, pois quase não existia fiscalização. Principalmente na década de 1970, vários caminhões de mudança atravessavam o limite todos os dias, uns ficavam nas cidades e vilas fronteiriças e outros desapareciam no mato, cobertos pela poeira vermelha das primeiras estradas.

Mas nem todos os que foram para o Paraguai conseguiram permanecer naquele país. Nas décadas de 1980 e 1990, milhares desses brasileiros voltaram para o Brasil, enquanto outros, principalmente jovens do Estado do Paraná, continuaram se dirigindo ao país vizinho atraídos pela possibilidade de trabalho no setor comercial e de serviços nas pequenas cidades paraguaias “colonizadas” por brasileiros.

Os imigrantes se concentraram nos departamentos paraguaios que são limítrofes com o Brasil (Alto Paraná, Canindeyú e Amambay) e também nos departamentos de Itapua, Caaguazu e Caazapá. Conforme dados do último censo paraguaio de 2002, somente 81.592 imigrantes brasileiros foram registrados (dados bastante distintos daqueles do Ministério das Relações Exteriores do Brasil); destes, 72.795 vivem nesses departamentos, sendo 37.226 em Alto Paraná, 16.171 em Canindeyú, 5.954 em Amambay, 5.253 em Itapua, 4.184 em Caaguazu e 2.308 em Caazapá (Paraguay, 2004a, p. 179).

Nessas regiões se formaram, ao longo das quatro últimas décadas, várias colônias e pequenas cidades, localizadas ao sul e ao norte de Ciudad del Este. Os moradores mantêm variados vínculos comerciais, familiares e de serviços sociais com as cidades de Foz do Iguaçu e Ciudad del Este. A cidade de Foz do Iguaçu funciona com o lugar privilegiado de acesso a direitos sociais, civis e 
políticos para essa ampla "comunidade de brasileiros" que vive do outro lado da fronteira política. Além disso, novos fluxos de migrantes jovens vindos de pequenas cidades brasileiras próximas a Foz do Iguaçu se deslocam para essas cidades paraguaias de forte presença brasileira e aumentam os fluxos entre o Brasil e o Paraguai.

Os imigrantes brasileiros, que conseguiram ascender socialmente ao longo das últimas décadas, controlam setores importantes da economia, da política e da cultura local em algumas cidades paraguaias (Santa Rita, Santa Rosa de Monday, Naranjal, San Alberto, etc.). A partir do final da década de 1970 e início dos anos 1980, ampliam-se os processos de mecanização e de concentração da propriedade da terra nessa faixa de fronteira. Uma família de agricultores podia aumentar o plantio sem necessitar contratar mais mão-de-obra. Nesse contexto, aumentam as compras de terra aos camponeses paraguaios e aos pequenos produtores brasileiros. A pequena produção diversificada e de subsistência (milho, mandioca etc.) passa a ser substituída pelo plantio de soja. Nesse processo, começam os deslocamentos de camponeses paraguaios e brasileiros para outras frentes agrícolas no interior do Paraguai e para as periferias das cidades de fronteira.

Esses brasileiros não adquirem somente poder econômico, tornam-se também candidatos ao poder político. Em 2005, existiam quatro prefeitos "brasiguaios" nessas pequenas cidades e vários vereadores brasileiros nos departamentos de Alto Paraná e Canindeyú. Os políticos brasileiros no Paraguai começaram a vida política ainda no período da ditadura de Stroessner (19541989) como secretários de alguma seção do Partido Colorado. No contexto democrático, as colônias e vilas fundadas por brasileiros se tornaram municípios. Desde então os brasileiros começaram a se candidatar e a se eleger em número crescente a cada eleição.

Os jovens prefeitos "brasiguaios" se apresentam como modernos e relatam que estão rompendo com a cultura política corrupta e autoritária da sociedade paraguaia. Há um discurso bastante aceito entre os imigrantes e seus descendentes de que o Paraguai só vai mudar e se modernizar quando esses ocuparem os principais cargos políticos municipais e nacionais:

Eu digo para você dentro de quatro ou cinco anos vai ter uma renovação dentro do Paraguai que são os filhos desses imigrantes tomando toda a parte política. Hoje nós temos aqui no distrito de Naranjal, onde eu moro, nós temos um 
prefeito de 25 anos. Ele é filho de imigrante, filho de brasileiro, mãe argentina, e são todos descendentes de alemão ali. Então é uma renovação, o que ele fez, é uma política jovem. Já tem senador que é descendente de alemão, só que eles são uma minoria, mas cada dia estão crescendo mais e vai chegar num momento que vão mudar essa mentalidade. (Líder do movimento jovem da Congregação Scalabrini, Santa Rita, Paraguai, entrevistado em 19 de novembro de 2004).

Os imigrantes não estão presentes somente no poder econômico e político local. É bastante significativa a influência cultural (língua portuguesa, meios de comunicação, religião, música, danças, tradições e culinária) do Brasil nessa ampla zona de fronteira. As músicas tocadas nos bares e nos carros de som são predominantemente brasileiras e os grupos musicais que vão tocar nos bailes são contratados geralmente no Brasil. Nas festas da Exposoja, que ocorrem nessas localidades, predomina a "cultura brasileira”, do idioma à culinária. As danças gaúchas são divulgadas e apreciadas nos Centros de Tradições Gaúchas (CTG) que existem em algumas cidades, como no caso do Centro Índio José em Santa Rita. Os meios de comunicação, principalmente os canais de TV brasileiros, reforçam a presença do português nessas regiões nos últimos 20 anos. As estradas asfaltadas e a compra de antenas parabólicas durante a década de 1990 aproximaram esses imigrantes do Brasil. Atualmente, quase todos os "brasiguaios" conseguem antenas parabólicas. Portanto, é a imagem do Brasil que está presente no cotidiano desses moradores fronteiriços. Embora os jovens e as crianças estudem espanhol, história e geografia paraguaias na escola, muitas referências cotidianas são emitidas do Brasil via satélite.

O forte poder econômico, político e cultural dos “brasiguaios” tem produzido uma reação do movimento camponês e de políticos de oposição, intelectuais, jornalistas e religiosos do Paraguai. Os confrontos entre empresários da soja e alguns setores da sociedade paraguaia têm gerado vários conflitos e disputas de identificações e representações variadas entre brasileiros e paraguaios.

\section{Conflitos na fronteira e representações sobre o "outro"}

A maioria dos conflitos que ocorreu, nas duas últimas décadas, na fronteira leste do Paraguai foi ocasionada por disputas de terra entre os movimentos camponeses paraguaios e imigrantes brasileiros que são proprietários de 
fazendas naquele país. A respeito disso, algumas observações preliminares são importantes: 1) os movimentos camponeses, embora "invadam" predominantemente as propriedades dos imigrantes brasileiros, também ocupam grande número de outros estrangeiros que vivem no Paraguai (alemães, menonitas, árabes, coreanos, chineses e norte-americanos) e dos próprios latifundiários paraguaios, principalmente de militares que conseguiram grandes faixas de terra durante a ditadura de Stroessner; 2) os conflitos envolvendo "brasiguaios” e campesinos não se resumem à disputa pela terra; estão relacionados à destruição florestal e uso de agrotóxicos nas lavouras de soja, bem como ao confronto político entre camponeses e prefeitos "brasiguaios".

Os camponeses sem-terra falam da necessidade de recuperar as terras malhabidas (ilegais) dos imigrantes brasileiros e passam a ocupar prioritariamente essas fazendas na região de fronteira. Embora a maioria dos "brasiguaios” tenha comprado essas propriedades das empresas colonizadoras, do próprio Instituto de Bienestar Rural (IBR) e dos camponeses paraguaios, alguns não têm as escrituras públicas e continuam somente com os contratos de compra e venda. Além disso, as terras geralmente têm vários documentos, fruto da corrupção política produzida no período ditatorial. A forte corrupção no IBR possibilitava a distribuição da mesma propriedade para mais de um proprietário, ocasionando sérios problemas de documentação. Os títulos são geralmente questionados e às vezes aparecem outros indivíduos se dizendo donos das terras. Além disso, os empresários agrícolas brasileiros, na expansão de suas fazendas, estão comprando ilegalmente dos camponeses paraguaios as derecheras, ${ }^{2}$ pois são bem mais baratas que as outras propriedades. As lideranças camponesas e alguns líderes políticos de oposição questionam essas transações imobiliárias e incentivam as ocupações dessas propriedades rurais. Esses conflitos foram bastante intensos em

\footnotetext{
2 Cada derechera corresponde a uma área de sete a dez hectares de terra, custa ao redor de um milhão de guaranis (500 reais) e pode ser paga em cinco anos ao IBR. Os brasileiros compram essa derechera da seguinte forma: pagam uma quantidade de dinheiro ao camponês para que este transfira o direito de propriedade, vão ao instituto e pagam as anuidades, no final conseguem o título de propriedade. Os imigrantes podem conseguir até cem hectares num mesmo quadrado. Mas após o término do pagamento, a escritura definitiva pode demorar até dez anos para estar pronta. Nesse período podem existir várias "invasões".
} 
2004, época de discussão da lei fronteiriça, e em 2008, após a posse do presidente Fernando Lugo. ${ }^{3}$

Os conflitos pela terra na região de fronteira possibilitaram a retomada, discussão e aprovação, pelo congresso paraguaio, de uma nova lei fronteiriça em 2004. A lei não atinge direitos adquiridos e está restrita à proibição da compra de imóveis rurais por estrangeiros dos países limítrofes numa faixa de $50 \mathrm{~km}$ a partir da linha de fronteira, diferente das versões anteriores do projeto que indicavam claramente a desapropriação de terras dos estrangeiros em toda essa faixa fronteiriça de segurança nacional (Paraguay, 2004b). A lei anterior tinha sido extinta na década de 1960, permitindo a venda de terras nessa faixa para os brasileiros e outros estrangeiros. O Brasil e a Argentina continuaram com essas faixas exclusivas (150 km e $100 \mathrm{~km}$ respectivamente) e esse era o principal argumento para aprovação de uma nova lei de defesa do território fronteiriço. Tudo indica que os imigrantes brasileiros continuam negociando suas propriedades nessa zona fronteiriça, transferindo os documentos para os filhos e netos que já têm cidadania paraguaia.

O problema relacionado ao meio ambiente e à intoxicação de camponeses nessas áreas de plantio de soja também tem gerado muitos conflitos com os camponeses. O aumento extensivo do território utilizado para o plantio mecanizado da soja gera uma ampliação intensiva do uso de agrotóxicos, aceleração do desmatamento e da poluição dos leitos de rios e riachos. As pulverizações terminam atingindo as comunidades camponesas. Os pequenos produtores e os camponeses sem-terra lutam principalmente com os grandes proprietários estrangeiros. Muitas vezes, eles param as máquinas de pulverização e enfrentam os fazendeiros e a polícia paraguaia.

A disputa pela terra e as reações aos novos plantios de soja transgênica são os cenários privilegiados dos conflitos e de variadas formas de resistência. Entretanto, a ascensão política de alguns imigrantes ou descendentes ao cargo de prefeito de algumas cidades também tem ocasionado algumas reações conflituosas com grupos de camponeses paraguaios. Na campanha política,

\footnotetext{
Fernando Lugo foi eleito em abril e tomou posse em agosto de 2008. Chegou à presidência prometendo realizar a reforma agrária naquele país e contou com o apoio de várias entidades camponesas e de inúmeros movimentos sociais. Esses movimentos camponeses começam a pressionar o novo governante, mediante novas ocupações de propriedades de paraguaios, "brasiguaios” e outros estrangeiros, para que ele realize a reforma agrária prometida.
} 
os quatro prefeitos “brasiguaios” enfrentaram adversários paraguaios, e os discursos da oposição enfatizavam que se os brasileiros ganhassem só iam beneficiar os imigrantes. Alguns opositores afirmavam que aqueles candidatos, caso fossem eleitos, iriam trocar a bandeira paraguaia pela brasileira tanto na prefeitura como nas escolas. Nos municípios de Mbaracayu, Santa Rosa e Naranjal, as disputas e troca de acusações se restringiram mais ao período eleitoral, mas no município de San Alberto os conflitos entre camponeses e prefeitura se estenderam por duas administrações.

Nesses cenários específicos de tensões relacionadas à terra, ao meio ambiente e ao poder político local, a fronteira "brasiguaia” pode ser vista como um campo de conflitos de classes, disputas étnicas, tensões nacionalistas e choque entre a civilização capitalista ocidental e as culturas camponesas e indígenas. As fronteiras podem ser entendidas aqui como marcos de diferenças sociais.

Os "brasiguaios" pertencem a diferentes classes e desenvolvem variadas profissões nesse território fronteiriço. As várias fronteiras sociais entre as classes desses imigrantes, ocasionada pelos processos de mobilidade social, somente seriam compreendidas mediante novas pesquisas quantitativas e qualitativas. ${ }^{4} \mathrm{O}$ que explicito aqui são os modos como os agentes sociais em confronto constroem a polaridade da classe e da nação entre campesinos paraguaios pobres e "brasiguaios” ricos (Fogel, 2008, p. 277). Os camponeses paraguaios e os imigrantes brasileiros que possuem grandes plantios de soja estão situados em campos diferentes da estrutura agrária. Não se trata da clássica contrariedade capitalista entre os empresários e os trabalhadores assalariados. Os conflitos não são em torno de salários, mas da posse da terra. As ações políticas da classe camponesa se efetivam mediante a formação de

4 Na tentativa de elaborar uma possível estratificação social, Sprandel (2000) define seis grupos de brasileiros no Paraguai: 1) proprietários de terras, comerciantes e madeireiros, com documentos regularizados e estratégias de integração plena na vida política e econômica local; 2) pequenos proprietários de terra com algumas outras atividades (arrendamentos, assalariado rural, motorista de caminhão e de máquinas agrícolas), espalhadas por toda a faixa de fronteira; 3 ) empregados nos setores agrícola, comercial e madeireiro; 4) ex-arrendatários em Alto Paraná que hoje são peões que trabalham em outros departamentos de forte presença brasileira; 5) os que estão em situação marginal (prostitutas, prisioneiros, meninos e meninas em situação de risco, etc.); e 6) aqueles ligados ao crime organizado (quadrilhas de roubo de carros, tráfico de drogas, recrutamento de prostitutas e jogos de azar). 
ações coletivas que reivindicam o direito à terra ocupada por "estrangeiros" na faixa de fronteira.

Os confrontos entre brasileiros, vários descendentes de alemães e italianos, e camponeses paraguaios com forte herança indígena podem ser vistos também como conflitos interétnicos. As comunidades de imigrantes são geralmente definidas pela sociologia e antropologia como grupos étnicos. A crença subjetiva numa comunhão e as lembranças de origem comum acentuariam, nos imigrantes, o sentimento de pertença a uma comunidade com diferentes costumes e outros aspectos externos de diferenciação (Weber, 1994). Os contrastes entre esses "grupos étnicos" acentuam as identificações coletivas, os preconceitos e formas negativas de classificação do "outro".

No contexto dessas disputas simbólicas, algumas palavras são criadas e/ou ressignificadas visando classificar negativamente o "outro". Os termos "chiru” e "rapai” são usados como expressões negativas para nomear os paraguaios e os brasileiros nesse cenário de fronteiras. Essas palavras têm sentidos positivos em cada idioma nacional, mas são modificadas na fonética e na semântica por brasileiros e paraguaios como uma forma de classificação negativa do "outro”. Assim, “che iru”, que em guarani significa "meu amigo”, "meu companheiro", os brasileiros mudam para "chiru” ou "chiru mandioqueiro”, e passa a ser um termo pejorativo ("bugre”, "índio”, "não civilizado”, etc.). De mesma forma, a palavra portuguesa "rapaz" (“jovem”, "moço”, muitas vezes usada como termo genérico para se referir ao outro em qualquer conversa cotidiana) se transforma em "rapai” na linguagem paraguaia e também adquire um sentido depreciativo ("ignorante", "inculto", etc.).

As disputas entre camponeses e plantadores de soja se transformam, muitas vezes, num confronto nacionalista. Os sentimentos nacionalistas em relação ao território e à língua guarani e os ressentimentos do período da Guerra da Tríplice Aliança (1865-1870) afloram nos discursos dos camponeses paraguaios. Os brasileiros são acusados de "invasores”, "novos bandeirantes”, "herança de Stroessner”, etc. Por sua vez, os imigrantes brasileiros assumem também uma postura nacionalista e destacam sua superioridade tecnológica e cultural. Eles se autodefinem como "trabalhadores", "pioneiros" e pertencentes a um país mais desenvolvido.

Nos contextos conflituosos de forte expressão nacionalista, os imigrantes brasileiros geralmente enfatizam o tamanho do território e o desenvolvimento tecnológico e econômico do Brasil comparado com os outros países vizinhos. 
Além disso, a "nação brasileira” é vista como uma "grande potência” por muitos paraguaios que não participam dos movimentos camponeses e que não estão em conflito com empresários "brasiguaios":

Porque el Brasil es una potencia, quiera o no. Brasil es una potencia en Sudamérica. A Brasil falta poco para que sea Estados Unidos, para que sea los yanques aquí en América [...] Piense que tiene el Brasil: tiene millones de kilómetros cuadrados, tiene océano por todos los lados, tiene costa por todos los lados, tiene mineral, visto que el petróleo de Brasil es autosuficiente, casi para todo. Brasil es un de los pocos países del mundo que inviste muchísimo en la educación de su gente, en la preparación de su gente. (Diretor escolar, San Alberto, Paraguai, entrevistado em 17 de janeiro de 2004).

No contraste fronteiriço, muitos brasileiros são reconhecidos e se consideram superiores e melhores. O sentimento e o orgulho nacional são fortalecidos na comparação direta com os outros países menores.

Por sua vez, o nacionalismo de alguns países vizinhos, especialmente do Paraguai, se constitui como uma espécie de reação às políticas dos países mais poderosos da região. $\mathrm{O}$ nacionalismo paraguaio se firma no contraste com a Argentina e com o Brasil desde o período de sua independência em 1811. Ele está relacionado à noção de resistência militar e cultural e manifesta-se mediante as memórias das guerras - Guerra da Tríplice Aliança (1865-70) e Guerra do Chaco (1932-35) - e da defesa da língua guarani como elemento cultural que distingue a nação paraguaia dos demais países limítrofes.

Os conflitos sociais no Leste do Paraguai ocasionam tensões culturais. A imagem do Brasil como uma nação moderna, civilizada e superior aos países vizinhos está presente na ideologia de muitos "brasiguaios" que se confrontam com as culturas camponesas e indígenas daquele país. Eles se apresentam como "missionários" da civilização e estariam ensinando aos paraguaios como se tornarem "modernos" e "trabalhadores". Os conflitos culturais entre imigrantes e paraguaios e os estereótipos construídos nesse cenário de fronteiras aumentam as tensões cotidianas. A autoidentificação dos imigrantes como "trabalhadores”, "pioneiros” e a classificação dos paraguaios como "preguiçosos", “corruptos” e "sujos” simbolizam assimetrias de poder entre os grupos locais e as nações. Contudo, as relações de poder não são estáticas e consolidadas. Os grupos subordinados podem adquirir força política e atacar os interesses dos grupos estabelecidos. Os movimentos camponeses têm reagido 
contra essas classificações pejorativas atribuídas pelos imigrantes brasileiros, por outros estrangeiros e por setores da elite política e econômica paraguaia.

Entretanto, nem tudo pode ser visto como conflito e produção de diferenças sociais, culturais e simbólicas. Há espaços sociais de cruzamentos e hibridismos culturais entre "brasiguaios” e população paraguaia. Nos espaços urbanos os conflitos são menos visíveis e podem ser construídos lugares comuns de convivência. Além disso, a própria relação conflituosa descrita acima tem gerado mudanças em relação ao maior cuidado no uso cotidiano da língua espanhola por parte desses imigrantes e o respeito aos símbolos nacionais paraguaios (hino e bandeiras nacionais) em algumas cidades fronteiriças. As fronteiras em movimento são também espaços de muitos fluxos culturais.

\section{Integração, conflito e hibridismo cultural}

Nos discursos que enfatizam as "relações cordiais” entre os brasileiros e os paraguaios, os conflitos são vistos como desavenças passageiras e somente existiriam em outras localidades por causa de determinados políticos que incentivam os campesinos. "Aqui é tudo mistura, tanto na língua como no convívio com os paraguaios” (Diretor escolar, San Alberto, Paraguai, entrevistado em 17 de janeiro de 2004). Nessa perspectiva, o que estaria ocorrendo é a construção de uma nova "sociedade mestiça" e de "cultura fronteiriça" fundamentada no "portunhol” (português e espanhol) ou "portuguaranhol” (hibridismo de português, guarani e espanhol). No hábito dos brasileiros tomarem o tererê (bebida fria feita com erva-mate e semelhante ao chimarrão do Sul do Brasil), na realização de casamentos entre indivíduos de distintas nacionalidades e no nascimento de filhos mestiços entre brasileiros(as), com ascendência europeia, e paraguaios(as) de origem indígena e espanhola (Feliú, 1999). O poema seguinte traduz a ideologia da harmonia e da integração desde o início da formação desse município de forte presença de imigrantes brasileiros:

\footnotetext{
A MI KATUETE

Fuiste colonizada por extranjeros

Con un soberbio nombre guaraní.

Seguros estaban ellos

Que en aquellas colinas,

Entre el Carapá y el Jaguati’y,
} 
Una pujante ciudad nacería allí.

Katuetê: "sem dúvida”, “seguros”;

Paraguayos e inmigrantes brasileños

Abrazados por la fuerza de la unión,

Construyeron en el corazón del Kanindeyú

La ciudad de la integración.

Sin distinción, trabajando sin receso,

Paraguayos y brasileños demostraron que

De la integración nace el progreso.

Trabajando juntos,

Unidos por la amistad,

Construyeron con sacrificio

Y el sudor de la frente,

Esta magnífica ciudad,

KATUETÊ, MI QUERIDA KATUETÊ.

(Diego Esteban Terrazas apud Feliú, 1999, p. 76)

Os discursos que versam sobre a separação dos “brasiguaios” ou a completa integração não dão conta de uma realidade bem mais complexa e heterogênea. Tudo indica que são manifestações de disputas políticas e simbólicas mais sutis. Aqueles que falam da segregação dos “brasiguaios” geralmente pretendem criticar e denunciar a “invasão” desses brasileiros no território paraguaio. Por outro lado, os discursos da harmonia e da integração às vezes funcionam como formas de legitimação dessa imigração.

O que acontece na prática cotidiana é uma complexa relação entre situações de domínio econômico, político e cultural dos "brasiguaios”, de conflitos variados, de integração e de assimilação de valores culturais que variam muito conforme a localidade e as mudanças que têm ocorrido no desenvolvimento das cidades “colonizadas” pelos imigrantes. Nos municípios onde os "brasiguaios” são maioria,tendem a predominar os valores culturais destes, ou seja, são os paraguaios que se adaptam à “cultura brasileira” (idioma, música, danças). Porém, nas localidades onde os imigrantes são minoria, terminam aprendendo com mais rapidez e interesse o guarani e o espanhol e algumas manifestações culturais locais, inclusive porque se sentem mais pressionados a se comunicar nas línguas nativas. A diversificação das atividades econômicas nessas pequenas cidades tem atraído novos brasileiros, mas também paraguaios de outras regiões do país que vão atrás de emprego no comércio local. 
O contato diário entre brasileiros e paraguaios se intensifica, e aumentam as trocas culturais e as tensões e diferenças cotidianas:

Aqui tem muitas famílias, já brasileira casada com paraguaio, já tem uma integração. Só que em nossa região aqui, em Mbaracayu, o canal de televisão paraguaio não pega o sinal. Então você pega o sinal da televisão brasileira. As festas e os costumes tradicionais brasileiros que a gente cultiva aqui dentro. Isso cria um pouco de divergência e diferença, mas a gente na região aqui está totalmente integrada. Isso é um ponto negativo para quem vem de fora, uma festa aqui na nossa comunidade, toca-se música brasileira, paraguaia, mas muito pouca, a maioria é brasileira. As danças, o idioma que a gente utiliza aqui é o português. Nas escolas, 95\% dos alunos são brasileiros, são paraguaios, mas filhos de brasileiros, falam mais o português do que o espanhol. E isso eu acho que não é certo isso aí. Inclusive nas igrejas católicas, luterana, adventista, os cultos são todos feitos em idioma nacional, inclusive se estuda o guarani também na escola, é o segundo idioma oficial do Paraguai. Na parte das rádios, na comunicação da região aqui tem muita comunicação em português. (Prefeito de Mbaracayu, Paraguai, entrevistado em 25 de novembro de 2004).

Nesse trecho da entrevista estão presentes algumas contradições entre as noções de integração, divergência e diferença. Em dois momentos, o entrevistado enfatiza que já existe na cidade em que ele administrava uma total integração entre brasileiros e paraguaios: “aqui tem muitas famílias, já brasileira casada com paraguaio, já tem integração” e “a gente na região aqui está totalmente integrada". O prefeito destaca a presença dos idiomas nacionais (espanhol e guarani) nas escolas e do espanhol nas igrejas. Mas ao mesmo tempo justifica a influência cultural do Brasil, pois somente "pega o sinal da televisão brasileira”, “toca-se música brasileira”, “o idioma que a gente utiliza aqui é o português”, "nas escolas, 95\% dos alunos são brasileiros [...], falam mais o português do que o espanhol” e "aqui tem muita comunicação em português”. A tensão permanente nesse discurso é produto de uma percepção das ambiguidades desse universo cultural fronteiriço que não se “encaixa” nos modelos homogêneos de “cultura nacional”. Mas também é derivado de uma observação cotidiana das diferenças e separações, mesclada com os desejos políticos em uma integração plena, contidos em expressões avaliativas como “isso eu acho que não é certo isso aí”. 
A tensão entre segregação e integração se localiza também entre as gerações dos imigrantes, fenômeno bastante semelhante em outros processos migratórios. Os mais velhos continuam bastante separados e os preconceitos, ar de superioridade do imigrante e desconfianças mútuas inviabilizam muitos espaços comuns de convivência:

Eu acho que o imigrante que veio aqui, não todos, tem uma minoria muito importante que é impressionante como eles buscam se adaptar, como eles buscam aprender espanhol, como eles buscam respeitar o Paraguai e ajudar a crescer. Mas tem uma boa quantidade, eu acho que é uma maioria, que acha que não deve nenhuma satisfação para ninguém, vem aqui e fala, e fala a hora que quer e fala português na frente de qualquer um. Tem muita gente que chegou sem nada e se fez aqui. Pensa que tendo uma maquinaria e um bom pedaço de terra é um senhor, é um dono e esqueceu a parte da educação, a parte moral e um montão de coisas. (Prefeito de Naranjal, entrevistado em 19 de novembro de 2004).

As novas gerações se encontram principalmente no espaço da escola. Os filhos e netos dos imigrantes estão aprendendo aspectos da "cultura paraguaia” no ambiente escolar. Eles estudam as duas línguas oficiais do país (espanhol e guarani), a história e a geografia paraguaias, cantam o hino nacional e compartilham informações variadas com professores e colegas paraguaios, inclusive participam de projetos de "resgate" da "cultura nacional" (aprendendo música, folclore e culinária paraguaia). Essas crianças e jovens vivem em mundos culturais em confluência e recebem a influência cultural tanto do Brasil, no cotidiano das ruas, das casas e das imagens televisivas, como do Paraguai, especialmente no ambiente escolar.

Os primeiros núcleos de colonização brasileira são hoje espaços bastante urbanizados e que vêm passando por todas estas práticas de integração, processos de hibridização e de produção de novas tensões e segregações entre seus habitantes. Mas, nos lugares das novas fronteiras agrícolas de expansão do plantio de soja (Caazapá, Caaguazu, San Pedro, Amambay e Alto Paraguay), predominam os conflitos, as destruições ambientais e o desrespeito aos nativos. O problema é que essa realidade tão diversa é geralmente homogeneizada, congelada e distorcida mediante a generalização dos aspectos mais negativos ou positivos dos "brasiguaios” ou dos campesinos paraguaios. 


\section{0 termo "brasiguaio" e as identificações fronteiriças}

A relação entre conflito e integração nessas localidades de forte presença "brasiguaia” tem gerado disputas variadas nas formas de autoidentificação dos imigrantes e seus descendentes e na maneira como são classificados pelos paraguaios. As identificações às vezes são enfatizadas, mas também são ocultadas e negadas conforme o jogo de interesses presente na relação conflituosa ou harmoniosa com o outro. Os termos "brasileiro", "paraguaio" e "brasiguaio" são explicitados ou ocultados nessas relações fronteiriças. ${ }^{5}$

Os brasileiros no Paraguai são geralmente conhecidos como "brasiguaios”. À primeira vista, o termo poderia ser entendido como uma identificação fronteiriça e híbrida, formada a partir da junção de duas identificações nacionais, ou seja, seriam ao mesmo tempo brasileiros e paraguaios. Entretanto, os espaços de hibridismo cultural nessas cidades fronteiriças e na linguagem das novas gerações não se traduzem em hibridismo "identitário”. O termo "brasiguaio” adquiriu sentidos variados ao longo das duas últimas décadas, funcionando como uma identificação ambígua, situacional e negociada conforme os interesses que necessitavam ser explicitados ou ocultados.

A identificação "brasiguaia” é imprecisa e bastante mutável. Essa categoria nativa pode ser atribuída: 1) ao imigrante pobre que foi para o Paraguai, não conseguiu ascender socialmente e que, muitas vezes, regressou ao Brasil; 2) aos grandes fazendeiros brasileiros no Paraguai; 3) aos filhos dos imigrantes que já nasceram naquele país e têm a nacionalidade paraguaia; 4) aos imigrantes e seus descendentes que falam um "idioma fronteiriço” e mesclam outros elementos culturais dos dois países; 5) a todos os imigrantes brasileiros na nação vizinha.

\footnotetext{
5 Meu objetivo foi privilegiar as identificações nacionais na relação entre imigrantes e paraguaios, mas tenho consciência de que as formas de identificações são múltiplas nessa região de fronteiras. Entre os imigrantes predominam as classificações regionais: gaúcho, paranaense, cearense, nordestino, mineiro, paulista, etc. Os estereótipos em relação ao nordestino, nortista, catarinense ou ao mineiro são bastante comuns nesse ambiente de fronteira em que essas identificações regionais ocupam espaços econômicos, políticos e culturais desiguais em território paraguaio. Os gaúchos predominam na região de Santa Rita e são os que mais têm propriedades rurais, que estão na política e que divulgam sua cultura através do Centro de Tradição Gaúcha; já os nordestinos e mineiros são minoria e ocupam geralmente posições subalternas.
}

Horizontes Antropológicos, Porto Alegre, ano 15, n. 31, p. 137-166, jan./jun. 2009 
O termo foi criado em 1985, no período do retorno para o Brasil do primeiro grupo organizado de imigrantes brasileiros. Os "brasiguaios" teriam sido "expulsos" daquele país por causa da concentração da terra, da mecanização da agricultura, do fim dos contratos de arrendamento e dos créditos agrícolas durante a década de 1980 . A esperança na realização da reforma agrária no Brasil favoreceu a volta de imigrantes pobres que passaram a se organizar e lutar pelo direito à terra e à cidadania brasileira. Naquele período, Sérgio Cruz, deputado federal (PT) pelo Mato Grosso do Sul, cunhou o termo "brasiguaio" durante uma manifestação de imigrantes na cidade fronteiriça de Mundo Novo (MS).

- Então quer dizer que nós não temos os direitos dos paraguaios porque não somos paraguaios; não temos o direito dos brasileiros porque abandonamos o país. Mas, me digam uma coisa: afinal de contas, o que nós somos?

- Vocês são uns brasiguaios, uma mistura de brasileiros com paraguaios, homens sem pátria. (Wagner, 1990, p. 11).

Os grupos religiosos, a imprensa e os próprios "colonos” começaram a construir a identificação de "brasiguaio” como "vítima” de um duplo processo de "expulsão" nacional. O termo estava associado à condição de brasileiro, estrangeiro e pequeno agricultor expropriado dos direitos civis, políticos e sociais dos dois lados do limite internacional (Sprandel, 1992).

Entretanto, os "brasiguaios" passam a ser estigmatizados pelos setores estabelecidos da sociedade brasileira. Desde os primeiros acampamentos em 1985, eles são vistos como “indesejáveis”, “perigosos”, “forasteiros” pelas autoridades políticas, jurídicas e pelos latifundiários dos municípios brasileiros que fazem fronteira com o Paraguai. Esses setores privilegiados temiam que os "brasiguaios" retornassem em grande quantidade e ameaçassem a ordem social das cidades brasileiras. Eles são estigmatizados pela condição de pobreza e por estarem vindo do Paraguai.

A categoria "brasiguaio" adquire significados distintos para os camponeses paraguaios. Com o fim da ditadura de Stroessner em 1989, principia a reorganização política dos campesinos, que reivindicam o direito à terra e começam a "invadir" as propriedades dos fazendeiros brasileiros. A partir deste período, os "brasiguaios” são identificados pelos camponeses paraguaios e 
outros setores críticos como os usurpadores das propriedades que deveriam pertencer aos paraguaios. "Brasiguaio” significa então o grande proprietário invasor, destruidor da natureza e que usa agrotóxicos em suas plantações. O sentido aqui é totalmente oposto ao anterior, ou seja, a mesma categoria pode se referir a duas classes sociais distintas conforme o jogo político das classificações nos dois lados da fronteira política. Entretanto, nem todos os camponeses paraguaios atribuem esse único sentido. Para o secretário de Federación Nacional Campesina (FNC), os "brasiguaios" seriam tanto os pequenos produtores rurais como os grandes plantadores de soja que moram no Paraguai:

Nosotros caracterizamos en dos formas: hay los "brasiguayos” que vinieron a trabajar como peones que se convirtieron en pequeños productores que tiene 10, 20 hectáreas. [...] Eso seria una visión que nosotros tenemos caracterizado cuales son los "brasiguayos", los pequeños productores que vinieron como peón a trabajar y volvieron a su país. Nosotros defendemos inclusive eso y tenemos que ir organizando, si ellos quieren regresar a su país que regresen y que ataquen el latifundio de su país. Y los otros serian los grandes productores de soja que también algunos se convirtieron en "brasiguayos" y ahora ya son asentados en nuestro país. (Membro da Federación Nacional Campesina (FNC), entrevistado em 26 de outubro de 2004).

A palavra "brasiguaio" pode ser atribuída somente ao filho do imigrante brasileiro que nasceu no Paraguai e que tem a nacionalidade paraguaia. “'Brasiguaios’ são pessoas já nascidas no Paraguai, descendente de brasileiros que já são nascidos aqui” (Líder do movimento jovem da Congregação Scalabrini, entrevistado em 19 de novembro de 2004). No começo essa classificação se referia à ausência de cidadania nos dois países. O que caracterizaria o "brasiguaio" seria a comprovação da nacionalidade paraguaia ou da dupla cidadania. Novamente ocorre uma inversão de sentidos.

Os "brasiguaios” seriam ainda todos os imigrantes brasileiros já adaptados à "cultura paraguaia” ou aqueles brasileiros que voltaram para o Brasil e continuam com práticas e costumes da sociedade paraguaia. São aqueles que tomam o tererê e falam o "portunhol” ou o "portuguaranhol”. Essa mescla ocorre a partir de uma disputa entre a influência brasileira no ambiente familiar e a presença dos idiomas paraguaios na escola: 
Esta es una mezcla entre paraguayos y brasileños. Como ellos son hijos de inmigrantes, la influencia en la casa, todos los días papá y mamá les hablan en portugués, entonces ellos se sienten brasileños. Miran las teles, los canales brasileños se exaltan el nacionalismo y esto lo que sale: el Brasil es el más grande del mundo. Todos los días es exaltación del nacionalismo, totalmente todos los días en todos los canales de televisión. Entonces ellos miran canales de televisión brasileña, se sienten brasileños, sus padres son brasileños, hablan en portugués. Pero viene a la escuela, a la institución escolar y tienen que hablar en castellano, tienen que hablar el guaraní, tienen que practicar costumbres y tradiciones paraguayas, entonces se sienten paraguayos, saben bien que nacieron en Paraguay, viven en Paraguay y que tienen que sentirse paraguayos, pero pertenecen, sus padres son inmigrantes. Ahí viene la palabra "brasiguayo", una mezcla. (Professor de história, entrevistado em 25 de novembro de 2004).

Na interpretação do entrevistado, há uma identificação entre "cultura” e "identidade”. Nessa perspectiva, uma cultura híbrida produziria formas de identificação híbridas, como no caso da "identidade brasiguaia”. Entretanto, sua própria narrativa demonstra as sutilezas dos sentimentos de pertença e a configuração das identificações situacionais no espaço doméstico e escolar. Os hibridismos culturais não se traduzem necessariamente em formas híbridas de identificação (Grimson, 2004). A autoidentificação “brasiguaia” pode ser associada à noção de uma experiência social liminar e situacional. Para alguns imigrantes, o “brasiguaio” é o "meio termo”, isto é, o interstício ou a liminaridade (Turner, 1974) entre uma identificação brasileira em trânsito e uma nacionalidade paraguaia ainda não reconhecida:

“Brasiguaio” é um nome que eles puseram pra nós porque estamos aqui há muitos anos. Não somos nem brasileiros nem paraguaios. Então eles chamam de "brasiguaios”. Uma coisa difícil. A gente é brasileiro, mas ao mesmo tempo, eu pra mim me considero paraguaio, estou aqui, temos o documento brasileiro tudo também, mas é uma coisa difícil de responder. (Pequeno produtor rural, entrevistado em 16 de novembro de 2004).

Por último, os “brasiguaios” geralmente são vistos como todos os imigrantes brasileiros no Paraguai. Muitas reportagens de jornais e os próprios imigrantes reforçam essa compreensão genérica. Para o prefeito de Santa Rosa de Monday, o "brasiguaio” seria o imigrante que tem origem brasileira, é “trabalhador” e teve a oportunidade de vida no Paraguai: 
Talvez "brasiguaio" porque você tem a origem, você tem o sonho que veio do Brasil, tem o orgulho [...], talvez o "brasiguaio" que é o brasileiro que entrou se considera uma parte brasileiro, pela origem, pelo que aprendeu, pelo que trouxe, e paraguaio pelo que o país está dando [...]. Talvez é isso, "brasiguaio" porque trouxe uma herança do Brasil, que é a tendência de trabalhar, não é descansar, e paraguaio porque entrou num país que deu oportunidade, abriu espaço. (Prefeito de Santa Rosa de Monday, Paraguai, entrevistado em 18 de novembro de 2004).

Essas classificações não estão separadas e explicitadas na realidade social. Na verdade, em um mesmo discurso aparece mais de um sentido, ou seja, o "brasiguaio" pode ser entendido como o filho do imigrante registrado como paraguaio e já integrado à cultural local ou o grande proprietário agrícola brasileiro com a situação migratória regularizada naquele país. A separação apresentada deve ser entendida como um recurso heurístico para facilitar a compreensão desse fenômeno heterogêneo e dinâmico.

Os setores mais pobres dos imigrantes brasileiros aceitam e valorizam essa classificação como um critério importante para receber benefícios sociais nos dois países e de não se sentirem totalmente estrangeiros no Brasil e no Paraguai. Mas essa categoria de atribuição geralmente é estigmatizada e muitos imigrantes brasileiros afirmam que gostam mesmo é de serem chamados de brasileiros ou paraguaios. O termo "brasiguaio" não é aceito pelos brasileiros que têm algum recurso econômico ou poder político, pois a palavra está associada ainda àqueles que não têm documentos, pobres, marginalizados. A não aceitação dessa categoria por esses setores que ascenderam socialmente simboliza um critério de distinção de classe. É mais valorizado ser paraguaio que ser "brasiguaio”. Dessa forma, o termo "brasiguaio” vivencia e sintetiza a contraditória experiência de conflito e integração na região de fronteiras.

\section{A dinâmica das fronteiras "brasiguaias"}

Os deslocamentos e vivências de imigrantes brasileiros na região leste do Paraguai possibilitam refletir, de uma maneira mais abrangente, sobre os próprios significados das fronteiras políticas e sociais nesse cenário liminar entre duas nações. 
As fronteiras nacionais são fenômenos complexos, não se resumem a limites, divisas, tratados diplomáticos, nem podem ser simplificados como o lugar do narcotráfico e do contrabando. As fronteiras políticas são criações humanas, delimitadas e demarcadas sucessivamente de acordo com os processos de ocupação militar, demográfica, econômica, política e cultural que ocorrem nos territórios limítrofes.

As fronteiras políticas têm variados sentidos construídos pelas populações locais que vivenciam a experiência das travessias e dos controles estatais. Do ponto de vista dessas populações fronteiriças, outras fronteiras sociais são construídas através do comércio fronteiriço, das redes de amizades, familiares, de namoros e casamentos que atravessam os limites políticos. Essas fronteiras não são estáticas, mas estão em constante movimento de redefinição e negociação. Os deslocamentos dos "brasiguaios" produzem uma pluralidade de fronteiras (políticas, jurídicas, econômicas, culturais e simbólicas) entre classes, etnias, gênero, nações e civilizações. As fronteiras nacionais e sociais podem ser vistas como marcos de diferenças culturais entre as populações que se encontram em situações fronteiriças, mas também como espaços privilegiados de contato e de trocas materiais e simbólicas.

No primeiro sentido, os grupos étnicos e nacionais se distinguem a partir da organização política e social e da criação de diferenças culturais no contraste direto com outros grupos sociais. A mobilização política constrói sinais diacríticos e regras morais de inclusão e exclusão social. O intenso contato entre os grupos étnicos e nacionais não dissolve as diferenças culturais. Pelo contrário, as identificações são fortalecidas na zona de fronteiras (Barth, 1998).

Nesta perspectiva, o Estado nacional e os agentes locais fronteiriços constroem e redefinem as identificações nacionais, regionais e locais. A periferia da nação pode ser pensada como centro e as identificações nacionais se firmam mediante a relação cotidiana com indivíduos pertencentes a outras nações. O Estado nacional constrói os limites políticos e os agentes locais criam variados sentidos para esse limite estatal, criam outras fronteiras culturais e variadas formas de autoidentificação (classe, nação, gênero, raça, etc.) e de classificação dos outros (García Canclini, 2000; Grimson, 2000, 2003; Sahlins, 1991, 2000; Valcuende del Río, 1998; Vila, 2000a, 2000b). Nesse sentido, os variados conflitos de classe, étnicos, nacionalistas e civilizacionais entre "brasiguaios" e campesinos ajudam a perceber o fortalecimento de fronteiras mediante os discursos políticos, as narrativas e termos usados para nomear "nós” e os “outros". 
Entretanto, as fronteiras nacionais podem ser analisadas como espaços privilegiados de intercâmbios, de travessias, hibridismo e mestiçagem. As fronteiras seriam um campo singular de trânsito cultural e estão relacionadas com os atuais processos de globalização e de redefinição dos Estados nacionais. A fronteira é geralmente percebida como lugar de passagem, porosa e espaço de contatos culturais e trocas simbólicas (Anzaldúa, 1987; Hannerz, 1997; Michaelsen; Jonhson, 2003; Padrós, 2003; Schaffer, 1995). Na "cultura brasiguaia” há espaços de aproximação, integração e hibridismo cultural entre brasileiros e paraguaios que permitem construir imagens parciais dessas zonas fronteiriças. Entretanto, as culturas híbridas, que sinalizam formas de adaptação, de integração dos “brasiguaios” à “cultura paraguaia”, não significam que as diferenças, os nacionalismos e as identificações polares desapareçam nessa zona fronteiriça.

O que podemos perceber na experiência dos "brasiguaios” são processos simultâneos de hibridismo cultural e de afirmação de identificações nacionais e preconceitos mútuos. A fronteira é um espaço de tensão e contradição entre o cruzador de fronteiras e o reforçador de fronteiras e não está centrada apenas nas zonas fronteiriças próximas ao limite político. É importante pensar no amplo deslocamento de cidadãos de um país na zona de fronteira da nação vizinha, como no caso dos imigrantes brasileiros na região leste do Paraguai. Considero importante refletir sobre a dinâmica das fronteiras "brasiguaias" sintetizando as tensões e integrações sociais, culturais e simbólicas, discutidas anteriormente, e acrescentando a dimensão econômica e civilizacional das frentes de expansão.

As palavras inglesas border e frontier permitem diferenciar dois sentidos do termo fronteira: border seria a fronteira como divisão política e administrativa, já frontier é a ideia de expansão, de conquista, de movimento constante. A fronteira passa a ser entendida como uma zona de transição entre um espaço geográfico ocupado de maneira estável e contínua por uma sociedade nacional e um outro que, desde a perspectiva dominante dessa sociedade, se encontra livre, embora já esteja ocupado por povos indígenas, camponeses, posseiros, etc.

As frentes de expansão econômica e demográfica entram em conflito com outros grupos sociais e étnicos. O que ocorre são disputas variadas entre os “modernos" setores capitalistas e os grupos excluídos das frentes de expansão capitalista (Martins, 1997; Oliveira, 1972; Ribeiro, 1996; Velho, 1976). As frentes de expansão produzem outras fronteiras sociais, culturais e temporais 
na relação entre os ideólogos do progresso e as comunidades camponesas e indígenas. Os estudos sobre frentes de expansão enfatizaram principalmente os processos estratégicos e espontâneos de ocupação econômica dos "espaços vazios” no interior do Estado-Nação, especialmente na região amazônica, e o choque com as comunidades camponesas e indígenas. Meu propósito foi pensar na dinâmica dessas fronteiras econômicas, mas também sociais e simbólicas, para além dos limites políticos do Brasil.

As frentes de expansão no Paraguai reproduzem quase os mesmos processos contraditórios que acontecem na Amazônia e em outras regiões brasileiras. As denominadas fronteiras da civilização e da modernização não podem ser vistas somente a partir da lógica dos "pioneiros" que teimam em dizer que estão ocupando "terras livres”. Essas fronteiras agrícolas e comerciais produzem relações de superexploração do trabalho, como a escravidão indígena, e um conjunto de conflitos e destruições ambientais. As frentes de expansão da soja transgênica têm destruído culturas camponesas e indígenas e o uso inadequado de agrotóxicos tem ocasionado doenças em famílias camponesas e poluído os rios da região (Fogel, 2008). As terras indígenas no Paraguai são alvo dos plantadores de soja e madeireiros. Na concepção de uma antropóloga e missionária paraguaia, as principais vítimas dessa frente de expansão capitalista são os índios. Segundo ela, há 30 anos existiam 17 etnias e cerca de 30 mil índios nessa zona fronteiriça, atualmente não passam de 15 mil. Um fato agravante desse quadro é que o processo de modernização agrícola é acompanhado de práticas sociais bastante injustas, como a escravidão indígena:

Depois de passar por torturas físicas e psicológicas, eles são forçados a trabalhar quase sem remuneração em lavouras e carvoarias, a maioria de brasileiros. [...] Os brasileiros se associam a políticos influentes para expulsar os índios. Além de perder seu espaço, etnias como a Pai Tavytevã, Avá-guarani e Ache vêem sua cultura ser violentada pela imposição de costumes estrangeiros. (Antropóloga e missionária paraguaia apud Konig, 2004).

A utilização da noção de fronteiras em movimento compreende o sentido das frentes de expansão capitalistas e outros sentidos de fronteiras analisados anteriormente. O que propus foi pensar os fluxos dos "brasiguaios", as representações, identificações e hibridismos culturais nessa complexa região de fronteiras como uma dinâmica própria e instável que congrega a dimensão 
do conflito, da diferença, da integração e do poder entre os grupos locais e os Estados nacionais.

Dessa forma, a dinâmica de fronteiras possibilita pensar a experiência dos "brasiguaios" em seu deslocamento para o Paraguai como desdobramentos de frentes de expansão em território brasileiro. Mas, sobretudo, permite perceber o dinamismo das fronteiras como marcos de diferenças e de classificações sobre o "outro" (conflitos sociais, étnicos, nacionais e civilizacionais) e como espaços de integração, de variados hibridismos culturais, mobilidades sociais e identificações situacionais.

\section{Considerações finais}

A primeira impressão para aqueles que visitam essas "comunidades de brasileiros” é a sensação de que o limite internacional foi deslocado a partir da década de 1970. A região fronteiriça de forte presença de imigrantes brasileiros seria "um pedaço do Brasil no Paraguai” ou "um Estado dentro do outro". Contudo, o fenômeno é mais complexo. O processo migratório ocasionou um alargamento da região de fronteira entre os dois países e ampliou os fluxos entre as cidades da Tríplice Fronteira. Estamos acostumados a pensar a zona de fronteira somente como o lugar situado nas imediações dos limites políticos, como no caso de Ciudad del Este-Foz do Iguaçu-Puerto Iguazu. Todos os fenômenos de hibridismo cultural e de afirmação de identificações nacionais que ocorrem em cidades classicamente definidas como fronteiriças acontecem também nesses municípios que estão situados num raio de até 100 km ou mais do limite internacional, como Santa Rita, Naranjal, Santa Rosa, San Alberto, Mbaracayu, etc.

Embora os Estados estabeleçam suas zonas oficiais de segurança e soberania nacionais, as fronteiras não são bem definidas nessa ampla região entre o Paraguai e o Brasil. O Estado paraguaio está presente mediante a reivindicação do monopólio da lei, das armas e do sistema educacional. Contudo, a "nação brasileira” também se encontra mediante o predomínio da língua portuguesa, das tradições culturais e dos meios de comunicação de massa. Esse amplo território de fronteira é, ao mesmo tempo, um espaço em que se fundem nações e, portanto, de muitos hibridismos culturais, mas também um lugar de disputa política e econômica entre países com desenvolvimento econômico desigual. 
O desequilíbrio de poder entre as nações se reflete nas microrrelações sociais entre os moradores dessa região fronteiriça.

O "espaço brasiguaio" (Souchaud, 2002) se configura como um singular universo de relações sociais e de circulação de pessoas e mercadorias entre dois Estados nacionais. A dinâmica das fronteiras "brasiguaias” são, portanto, espaços sociais de integração, tensão e poder. Novos estudos sobre os deslocamentos de populações em outros lugares de fronteira podem contribuir para o desenvolvimento de outras abordagens sobre a especificidade das regiões de fronteira entre os Estados nacionais na América do Sul. Nesses territórios fronteiriços, os habitantes de cada país entram em contato - tanto harmonioso como conflituoso - com os vizinhos, e na relação entre "nós” e “eles” é produzido todo um conjunto de representações e configurações sociais possíveis.

\section{Referências}

ABÍNZANO, R. C. Antropología de los procesos transfronteirizos: conocer y actuar en la región de fronteras. Cuadernos de la Frontera, Posadas, año 1, n. 1, p. 1-44, mar. 2004.

ALBUQUERQUE, J. L. C. Fronteiras em movimento e identidades nacionais: a imigração brasileira no Paraguai. Tese (Doutorado em Sociologia)-Programa de Pós-Graduação em Sociologia, Universidade Federal do Ceará, Fortaleza, 2005.

ANZALDÚA, G. Borderlands/la frontera: the new mestiza. San Francisco: Aunt Lute, 1987.

BARTH, F. Grupos étnicos e suas fronteiras. In: POUTIGNAT, P.; STREIFFFENART, J. Teorias da etnicidade. São Paulo: Unesp, 1998. p. 187-227.

FELIÚ, F. Canindeyu-zona alta: los brasiguayos. Asunción: Leo SRL, 1999.

FOGEL, R. La región de la triple frontera: territorios de integración y desintegración. Sociologias, Porto Alegre, n. 20, p. 270-290, jul./dez. 2008.

GARCÍA, C. I. (Comp.). Fronteras: territorios y metáforas. Medellín: Hombre Nuevo Editores, 2003. 
GARCÍA CANCLINI, N. Culturas híbridas. Tradução de Ana Regina Lessa e Heloisa Pezza Cintrão. São Paulo: Edusp, 2000.

GRIMSON, A. (Org.). Fronteras, naciones e identidades: la periferia como centro. Buenos Aires: La Crujía, 2000.

GRIMSON, A. La nación en sus límites: contrabandistas y exiliados en la frontera Argentina-Brasil. Barcelona: Gedisa, 2003.

GRIMSON, A. Las culturas son más híbridas que las identificaciones. Conferência apresentada em Reflections on the Future. University of Califórnia, Santa Cruz, fev. 2004.

HANNERZ, U. Fluxos, fronteiras, híbridos: palavras-chave da antropologia transnacional. Mana: Estudos de Antropologia Social, v.. 3, n. 1, p. 7-39, abr. 1997.

KONIG, M. Nova colonização ameaça povos indígenas. Gazeta do Povo, Curitiba, p. 10a, 14 jan. 2004.

MARTINS, J. de S. Fronteira: a degradação do outro nos confins do humano. São Paulo: Hucitec, 1997.

MATTOS, C. de M. Geopolítica e teoria de fronteiras: fronteiras do Brasil. Rio de Janeiro: Biblioteca do Exército, 1990.

MICHAELSEN, S.; JOHNSON, D. E. (Comp.). Teoría de la frontera: los límites de la política cultural. Traducción de Gabriela Ventureira. Buenos Aires: Gedisa, 2003.

OLIVEIRA, R. C. O índio e o mundo dos brancos. São Paulo: Pioneira, 1972.

PADRÓS, E. S. Fronteiras e integração fronteiriça: elementos para uma abordagem conceitual. Humanas: Revista do Instituto de Filosofia e Ciências Humanas/UFRGS, v. 16, n. 1, p. 63-85, jan./jun. 2003.

PARAGUAY. Resultados finales Censo Nacional de Población y Viviendas: año 2002 - total país. Asunción: DGEEC, 2004a. 
PARAGUAY. Ley 2532. Que establece la zona de seguridad fronteriza de la Republica del Paraguay. Asunción, 9 dic. 2004b.

RIBEIRO, D. Os índios e a civilização. Rio de Janeiro: Civilização Brasileira, 1996.

SAHLINS, P. Boundaries: the making of France and Spain in the Pyrenees. Berkeley: University of California Press, 1991.

SAHLINS, P. Repensando Boundaries. In: GRIMSON, A. (Org.). Fronteras, naciones e identidades: la periferia como centro. Buenos Aires: La Crujía, 2000. p. 41-49.

SCHAFFER, N. O. Globalização e fronteira. In: SCHAFFER, N. O. Práticas de integração nas fronteiras: temas para o Mercosul. Porto Alegre: Editora da UFRGS, 1995. p. 79-91.

SOARES, T. História da formação das fronteiras do Brasil. Rio de Janeiro: Conselho Federal de Cultura, 1972.

SOUCHAUD, S. Pionniers brésiliens au Paraguay. Paris: Karthala, 2002.

SPRANDEL, M. A. Brasiguaios: conflito e identidade em fronteiras internacionais. Dissertação (Mestrado em Antropologia Social)-Museu Nacional/Universidade Federal do Rio de Janeiro, Rio de Janeiro, 1992.

SPRANDEL, M. A. Brasiguayos: una identidad de frontera y sus transformaciones. In: GRIMSON, A. (Org.). Fronteras, naciones e identidades: la periferia como centro. Buenos Aires: La Crujía, 2000. p. 299-320.

SPRANDEL, M. A. “Aqui não é como na casa da gente”: comparando agricultores brasileiros na Argentina e no Paraguai. In: FRIGERIO, A.; RIBEIRO, G. L. (Org.). Argentinos e brasileiros: encontros, imagens e estereótipos. Petrópolis: Vozes, 2002. p. 187-207.

TURNER, V. O processo ritual: estrutura e antiestrutura. Petrópolis: Vozes, 1974.

VALCUENDE DEL RÍO, J. M. Fronteras, territorios e identificaciones coletivas. Sevilla: Fundación Blas Infante, 1998. 
VELHO, O. G. Capitalismo autoritário e campesinato: um estudo comparativo a partir da fronteira em movimento. São Paulo: Difel, 1976.

VILA, P. Crossing borders, reinforcing borders: social categories, metaphors and narratives identities on the U.S - Mexico Frontier. Austin: University of Texas Press, 2000a.

VILA, P. La teoría de frontera versión norteamericana: una crítica desde la etnografía. In: GRIMSON, A. (Org.). Fronteras, naciones e identidades: la periferia como centro. Buenos Aires: La Crujía, 2000b. p. 99-120.

WAGNER, C. Brasiguaios: homens sem pátria. Petrópolis: Vozes, 1990.

WEBER, M. Relações comunitárias étnicas. In: WEBER, M. Economia e sociedade: fundamentos da sociologia compreensiva: vol. 1. Tradução de Regis Barbosa e Karen Elsabe Barbosa. Brasília: UnB, 1994. p. 267-277. 